\title{
Padrões setoriais de aprendizagem da indústria brasileira: uma análise exploratória*
}

\section{Pablo Felipe Bittencourt}

Departamento de Economia e Relaçōes Internacionais da Universidade Federal de Santa Catarina (UFSC)

\section{RESUMO}

O objetivo deste artigo é identificar padrões setoriais de aprendizagem na indústria brasileira. A literatura evolucionária/neoschumpeteriana é utilizada como referencial teórico, ao passo que a metodologia contempla o uso de técnicas de análise multivariada, aplicadas a indicadores de aprendizagem construídos para 93 setores da atividade industrial brasileira, a partir de dados da Pesquisa Industrial de Inovação Tecnológica (Pintec), do IBGE. Os resultados revelaram quatro padrôes setoriais de aprendizagem que podem ser utilizados como referências para outras análises setoriais relacionadas ao tema.

PalaVras-Chave | Processo de Aprendizagem; Padrões Setoriais.

Código JEL | O33.

\footnotetext{
* Uma versão preliminar desse artigo foi apresentada no XXXVIII Encontro da Anpec. O autor agradece os comentários dos professores Jorge Brito, José Eduardo Cassiolato, Arlindo Villaschi Filho, Marco Vargas e Carlos Pinkusfeld, além dos pareceristas anônimos da RBI
} 


\title{
Sectoral patterns of learning in brazilian industry: an exploratory analysis
}

\begin{abstract}
The article aims to identify Sectoral Patterns of Learning in Brazilian Industry. The evolutionary/neoschumpeterian approach is used as a benchmark for theoretical, while the methodology involved the use of multivariate analysis techniques, applied to learning indicators constructed for 93 sectors of the Brazilian industrial activity. The Brazilian Innovation Survey (PINTEC) is the major data base used. The results revealed four sectoral patterns of learning that can be used in other studies of the same themes.
\end{abstract}

KEYWORDS | Learning Process; Sectoral Patterns

JEL-Code | O33.

\section{Introdução}

A inovação é um fenômeno explicado por fatores não lineares. Gerá-la exige, por parte da empresa, capacidade de reconhecimento do valor das informações externas e, mais do que isso, assimilá-las e traduzi-las para máquinas, equipamentos, materiais, componentes e produtos, de maneira que a combinação de conhecimentos novos com aqueles enraizados na empresa amplie seu estoque de conhecimentos relevantes e suas possibilidades de acessar outros. A interação com o ambiente é decisiva nesse processo.

Ainda que o processo aconteça de maneira muito particular em cada empresa, nesse trabalho parte-se da hipótese teórica de que regularidades podem ser abstraídas das firmas em relação a determinados fatores capazes de influenciar seu comportamento. $\mathrm{O}$ setor de atividade industrial em que a empresa opera é um desses fatores, sendo a variedade na base de conhecimentos (MALERBA; ORSENIGO, 1997) um exemplo de elemento que atua de diferentes maneiras sobre os setores, implicando multiplicidade nas formas de organização das atividades de aprendizagem. Avançando 
nessa linha de pesquisa, o objetivo do trabalho é identificar e analisar padrôes de aprendizagem das empresas brasileiras, utilizando os âmbitos de atividade industrial como parâmetro das "regularidades".

Além de contribuir com a compreensão sobre a dinâmica tecnológica setorial da indústria nacional, espera-se que os padrões setoriais de aprendizagem possam servir como referência de comparação entre aspectos relacionados à aprendizagem em outros trabalhos. A hipótese subjacente é a de que os grupos formados guardem características intrapadrão, que possam ser analisadas segundo elementos teóricos já definidos pela literatura especializada. Para isso, a técnica de clustering de análise estatística multivariada foi aplicada aos indicadores de aprendizagem (learning), construídos a partir das informações das Pesquisas de Inovação Tecnológica do IBGE: Pintecs I, II e III referentes a 1997-2000, 2001-2003 e 2003-2005, respectivamente.

$\mathrm{O}$ artigo está organizado em quatro seções, além desta introdução. $\mathrm{Na}$ seção seguinte, é discutida a fundamentação teórica e analítica evolucionária/neoschumpeteriana. A seguir, apresentam-se os procedimentos metodológicos utilizados e, posteriormente, são expostos e analisados os padrões resultantes da aplicação da técnica de cluster. A última seção traz as conclusões dessa discussão.

\section{Referencial teórico e analítico}

A principal noção pela qual se norteia este artigo define o aprendizado como um processo custoso para as empresas, derivado de fontes de conhecimento internas e externas, o qual resulta na ampliação do estoque de conhecimentos que se acumulam na firma (MALERBA, 1992). Trata-se de uma noção significativamente diferente da de Arrow (1962), para quem o aprendizado é um fenômeno cuja fonte de conhecimento é basicamente a experiência no âmbito da produção (learning by doing) e que não incorre em custos extras além daqueles típicos da atividade produtiva.

Segundo a noção evolucionária da dinâmica de produção da firma, os custos de aprendizagem estão associados a processos de busca capazes de diferenciar a empresa de seus concorrentes. Nesse contexto, a firma individual é encarada como um repositório de conhecimentos produtivo e tecnológico constantemente em busca de soluções mais vantajosas entre as diversas oportunidades possíveis. $\mathrm{O}$ processo decisório de cada empresa é influenciado pelas formas de organização e processamento interno de suas atividades, ou melhor, por suas rotinas (NELSON; WINTER, 1982). Partes dessas rotinas são desenvolvidas em um processo de interação com o ambiente concorrencial, por meio da introdução de inovações, da interação com 
clientes, da busca de novos nichos, entre outras. O processo resulta na transformação constante do ambiente devido à influência dos próprios agentes.

A tomada de decisões se processa, portanto, em um ambiente competitivo mutante, que influencia a configuração de diversidades comportamentais das empresas (TEECE; PISANO, 1994), gerando um ambiente marcado por assimetrias tecnológicas capazes de explicar essas diferentes capacidades entre empresas de um mesmo setor. Isso significa que, embora haja regularidades, existem componentes estocásticos, não teorizáveis (SILVERBERG et al., 1988).

Uma das tentativas mais conhecidas de teorizar sobre regularidades setoriais, particularmente sobre a mudança tecnológica, é a taxonomia de Pavitt (1984). O autor diferencia os setores dominados por fornecedores, baseados em ciência, e aqueles intensivos em produção, subdividindo estes últimos em fornecedores especializados e intensivos em escala. A taxonomia foi construída segundo as fontes, o impacto e a natureza das inovaçôes setoriais. Para isso, utilizaram-se como variáveis as fontes de conhecimento, o tamanho das empresas inovadoras, as características do processo produtivo e os setores que produzem e são usuários da inovação. No texto, seminal para qualquer estudo sobre características setoriais da inovação, o destaque é dado ao caráter cumulativo do conhecimento aplicado às inovações, sendo que a maior parte do conhecimento aplicado não tem objetivos genéricos, nem é facilmente transmitida ou reproduzível, mas sim adequada para aplicaçóes e apropriada por empresas específicas.

Posteriormente, o autor faz uma revisão dessa taxonomia, na qual inclui a categoria dos setores "intensivos em informação" e exclui a daqueles "dominados por fornecedores". A inclusão da primeira deve-se ao potencial inovador das oportunidades tecnológicas criadas pelas tecnologias computacionais, enquanto a exclusão da segunda ocorre pelo papel ativo dessas empresas na interação com fornecedores, tornando-os passíveis de reordenação em setores intensivos em escala ou intensivos em informação (PAVITT et al., 1989).

Em qualquer esforço de caracterização dos processos de inovação, a exploração de variáveis de aprendizagem é regra, uma vez que em seus processos de inovação as empresas combinam ${ }^{1}$ diferentes formas de aprendizado, as quais obedecem, por sua vez, a diferentes rotinas e características do ambiente em que estão inseridas. $\mathrm{Ou}$ seja, os processos de aprendizagem derivam não apenas daqueles em que as empresas

1 A própria ideia de aprendizado é concebida como um conjunto de atividades em que vários tipos de conhecimentos se (re) combinam para construir algo novo (ARROW, 1962). 
buscam por inovações, mas também de suas atividades rotineiras de produção, com aprendizado associado a learning by doing, by using e to learn, por exemplo.

A forma como a empresa interage (aprende) com o ambiente é, portanto, determinante para a construção do seu conjunto particular de conhecimentos. Tal construção explica, ao mesmo tempo, sua diferenciação no "mercado" e a presença de componente tácito, de difícil transmissão dos conhecimentos nela enraizados, o qual determina a capacidade de cada empresa de absorver e explorar (aprender) conhecimentos externos (LUNDVALL et al., 2001; COHEN; LEVINTHAL 1989).

A parcela tácita (não codificada do conhecimento) refere-se aos elementos como insights que ocorrem aos indivíduos e que, mesmo pelos detentores do conhecimento, não podem ser definidos plenamente. Mas podem, contudo, ser compartilhados entre colegas com experiências comuns. Tal transferência encontra grandes restrições em relações típicas daquelas realizadas por meio de contratos de mercado, por exemplo. ${ }^{2}$

Por outro lado, a absorção de insumos científicos, por serem públicos e amplamente codificados, depende apenas da capacidade dos interessados em interpretálos. É natural pensar, nesse sentido, que algumas atividades setoriais utilizem de maneira mais intensiva - mas não exclusivamente - um conjunto de informações científicas em seus processos de inovação. ${ }^{3}$ Estes conhecimentos codificados não estão restritos aos insumos científicos, mas se estendem a todo conhecimento que, de alguma forma, pode ser transformado em informação, seja por meio de registro em manuais, seja a partir de normas e procedimentos do cotidiano. $\mathrm{O}$ processo de codificação consiste na redução e conversão à informação, que permite aceleração dos processos de transmissão, armazenamento e reprodução do conhecimento (FORAY; COWAN, 1997).

A literatura apresenta quatro tipos de conhecimento que ajudam a compreender as distintas necessidades das empresas: o "saber o que"; o "saber por que"; o "saber como" e o "saber quem". Os dois primeiros surgem da leitura de livros, da participação de conferências, da consulta a bancos de dados, etc. Os demais baseiam-se nas experiências práticas, amadurecidas no cotidiano por meio de processos como "learning-by-doing" e "learning-by-interacting" (FORAY; LUNDVALL, 1999)

Jensen et al. (2007) destacam os conhecimentos tácitos, em que o "saber como" é obtido a partir de práticas de aprendizagem do tipo mestre-aprendiz, sendo que

2 O tempo, por exemplo, pode ser um fator inibidor das tentativas de absorver e imitar conhecimentos tácitos externos, à medida que não se possa fazê-lo com rapidez o suficiente para que os ganhos da inovação resultante seja explorável. Por isso, contextos sociais capazes de estimular interações sociais importam a esse processo (NONAKA, 1994).

3 Uma evidência empírica é a análise clássica de Nelson (1986). 
tanto a linguagem falada como a corporal do mestre auxiliam na compreensão do aprendiz. Práticas de treinamento no interior das empresas, por exemplo, estimulam a difusão desse tipo de conhecimento. Segundo os autores, o "saber como" que possuir know-how é o que caracteriza a mão de obra especializada e diferencia um cientista de alto nível. Já em relação ao "saber quem", eles destacam que esse tipo de conhecimento se aprende na prática, por meio da participação em comunidades de profissionais especializados, em conferências, sociedades profissionais, feiras, etc. Esses ambientes dão aos participantes acesso a discussões de experiências e informaçôes de seus colegas (CARTER, 1989 apud, JENSEN et al., 2007). Tais práticas podem envolver também clientes, contratantes e institutos independentes.

Nesse sentido, o aprendizado é visto como um processo capaz de construir novas competências e vantagens competitivas, em que a repetição, a experimentação e a busca de novas fontes de informação são mecanismos que capacitam tecnologicamente as empresas e estimulam a produção e a mudança técnica (LUNDVALL, 1992).

De acordo com Lundvall et al. (2001), a transmissão desses conhecimentos é resultado da interação entre agentes envolvidos em um contexto sociocultural e institucional específico, podendo a habilidade em aprender, no sentido de construir novas competências, ser decisiva para o desenvolvimento de indivíduos, empresas, regiōes e economias nacionais.

Malerba (1992) aponta o aprendizado tecnológico como a raiz da mudança incremental e sugere elementos analíticos para sua compreensão que se alinham à visão de Lundvall et al. (2001). Para aquele autor, o fenômeno deve ser analisado considerando-se quatro características básicas:

- trata-se de um "processo orientado" com custo específico, realizado no interior da empresa a partir da motivação de diversas dimensões organizacionais, com respeito a uma estratégia específica que explica as principais direções dos esforços de capacitação dos agentes;

- associa-se a diferentes fontes de conhecimento, internas e externas à empresa. Internamente, estas fontes relacionam-se a atividades específicas, como produção, P\&D e marketing; externamente, envolvem articulaçôes com fornecedores, consumidores e com a infraestrutura científico-tecnológica;

- é cumulativo e amplia o estoque de conhecimentos da empresa. Por haver diversas fontes de conhecimento, estas afetam diferentemente o estoque de conhecimentos das firmas;

- aos processos de aprendizagem não se relacionam apenas as inovações incrementais nos processos produtivos, mas também aquelas que possi- 
bilitam a expansão para novos mercados, a partir da exploração de novas oportunidades tecnológicas dos produtos gerados.

$\mathrm{O}$ autor ainda reconhece seis diferentes tipos de aprendizado, identificando suas formas peculiares de obtenção de conhecimentos:

- learning by doing - mais próximo à noção de Arrow (1962) - derivado da experiência interna acumulada pelos agentes via repetição das atividades produtivas; por isso, possibilita maior eficiência nos processos de produção, inclusive com a redução de seus custos;

- learning by using - relacionado ao uso de produtos, insumos e máquinas para o melhoramento de produtos e processos. Com essa forma de aprendizagem, podem ser identificadas características não percebíveis em testes de qualidade ou em simulações;

- learning from advances em S\&rT-associado ao avanço dos conhecimentos aplicáveis de ciência e tecnologia;

- learning from inter-industry spillovers - refere-se ao que as empresas concorrentes e outras da indústria estão fazendo;

- learning by interacting - determinado pela interação com fontes de conhecimento, tais como clientes, fornecedores de bens de capital e o restante da indústria. As interações entre fornecedores e usuários são destacadas, por diversos autores, como os relacionamentos mais importantes da esfera industrial para o desenvolvimento de inovações (VON HIPPEL, 1986; LUNDVALL, 1986; DYER, 1996);

- learning by searching - interno à empresa, estaria vinculado às atividades de pesquisa para a busca de novos conhecimentos, as quais seriam desenvolvidas no decorrer do processo de busca por soluçóes e oportunidades, considerando-se os problemas identificados.

Outra forma encontrada na literatura especializada é o learning to learn, que se vincula à identificação, na estrutura organizacional da empresa, de elementos que se colocam como limites ou oportunidades para o aprendizado. Teoricamente, a noção de learning to learn é derivada da ideia de aprendizagem organizacional, a qual destaca que o conhecimento enraizado nas organizaçôes é maior do que a soma dos conhecimentos dos indivíduos que dela fazem parte. Ocorre que, por meio do desenvolvimento (intencional ou não) de sistemas cognitivos, as organizações transmitem ao longo do tempo características de seu comportamento, normas e valores, independentemente das entradas e saídas de trabalhadores. 
Conforme Hedberberger (1981, p. 6), "Organizations do not have brains, but they have cognitive systems and memories". Nessa direção, esforços de treinamento significam tentativas de transmissão de conhecimentos tácitos enraizados de um grupo para outro grupo de indivíduos da empresa. Segundo Brown e Dugui (1991), o treinamento deve ser compreendido como a transmissão do conhecimento abstrato da cabeça daquele que possui o know-how para a cabeça daquele que, por não ter desenvolvido a rotina específica, não o possui. Além do treinamento interno, a busca externa de conhecimentos em centros de capacitação, como o Senai aqui no Brasil, configura-se como forma de ampliar as competências internas que podem ser caracterizadas como aprendizagem via treinamento e associam-se à noção de learning to learn.

Outra forma de aprendizagem corresponde ao learning by imitating, ${ }^{4}$ derivado do processo que visa reproduzir inovações desenvolvidas e/ou introduzidas por outra empresa, sem que tenha havido qualquer cooperação entre as duas firmas (KIM; NELSON, 2005). As imitações podem envolver desde falsificação até adaptações criativas e saltos tecnológicos. ${ }^{5}$ Um concorrente pode, portanto, servir de inspiração para avanços tecnológicos por meio do simples contato com o produto via engenharia reversa. Contudo, a imitação pode necessitar da aquisição da patente para ocorrer. A imitação por meio do contato com a inovação do concorrente está diretamente associada à necessidade de conhecimentos tácitos para a compreensão total do produto. Já a imitação via licenças, patentes e know-how envolve aquisição de conhecimentos codificados nessas, bem como um conjunto específico de conhecimentos tácitos que permitam ao imitador compreender o avanço patenteado e adaptá-lo à empresa.

A literatura ainda destaca o learning by hiring, que ocorre quando as empresas contratam trabalhadores (experts) de outras firmas. A relevância dessa forma de aprendizagem fica evidente quando se admite que o conhecimento é algo inerente ao ser humano e que, portanto, a mobilidade do trabalhador possui papel signifi-

4 Essa forma de aprendizagem foi intensamente utilizada na rápida industrialização de economias como a da Coréia do Sul, mas também da brasileira (entre outras) nas décadas de 1960 e 1970, especialmente através da engenharia reversa. Quando os produtos imitados são relativamente simples, a engenharia reversa não gera necessidade de investimentos em P\&D e o aprendizado é restrito. No entanto, o contrário também pode ocorrer. Conforme Nelson e Winter (1982, apud KIM; NELSON, 2005), quando trabalham com indícios muito restritos, os imitadores podem assumir a qualidade de inovadores, pois resolveram a maior parte do problema. Nesses casos, as atividades de engenharia reversa podem rapidamente se transformar em atividades de P\&D. As inovações podem também ser imitadas legalmente via aquisição de patentes, licenças e know-how. Masfield (1984 apud KIM; NELSON, 2005) revelou que $60 \%$ das inovações patenteadas foram imitadas em quatro anos a partir de seu surgimento.

5 Por se aproximarem muito da noção de "inovação" de Schumpeter, os saltos tecnológicos configuram-se em uma área nebulosa na identificação das inovações e simples difusões do progresso técnico. 
cativo no processo de aquisição e construção de conhecimentos das empresas, assim como nas possibilidades de aplicações de conhecimentos acumulados em diferentes contextos. $\mathrm{O}$ aprendizado by hiring está diretamente associado à importância do conhecimento tácito nos processos de inovação, uma vez que a contratação de um expert é considerada menos custosa para a firma do que outra forma de tentar desenvolver ou adquirir o conhecimento demandado. ${ }^{6}$

Os elementos que definem os padrōes de aprendizagem mostrados neste artigo são a maior ou a menor intensidade no uso das diferentes formas de aprendizagem mencionadas anteriormente. Trata-se de uma análise exploratória de dados que procura identificar padróes de aprendizagem por meio de indicadores específicos aplicados ao conjunto de empresas inovadoras, reunidas em $93^{7}$ atividades industriais (setores) da economia brasileira.

Algumas evidências da diferenciação setorial de aprendizagem são encontradas em Meeus et al. (1999), ao apontarem as atividades mais complexas como aquelas com maior demanda por interações com a infraestrutura de C\&T, além de outros elementos, como o destaque à intensidade do uso de recursos internos, qualificados para a ampliação do acesso a conhecimentos externos, confirmando a hipótese de Cohen e Levinthal (1989).

Também Levin (1988), por exemplo, diferencia setores ao investigar a hipótese de que haveria um desincentivo à realização de $\mathrm{P} \& \mathrm{D}$ interno (learning by search), provocado pela possibilidade de parte desse esforço ser apropriado por seus concorrentes por meio da troca de informações (learning by spillover), como parte da estratégia de acelerar o progresso técnico (SPENCE, 1984 apud LEVIN, 1988). Os resultados ratificam a hipótese para indústrias como as de farmácia e química, mas não para aquelas voltadas à fabricação de computadores, construção de aviōes, equipamentos de comunicação e componentes eletrônicos.

Já Murovec e Prodan (2009), em estudo sobre as indústrias espanholas e da República Tcheca, apontaram dois grupos de empresas cuja capacidade de absorção se definia pela intensidade da interação: science-push mode - empresas intensivas na absorção de conhecimentos de universidades; e demand-pull mode - firmas intensivas na absorção de conhecimentos de fornecedores, clientes e concorrentes.

No Brasil uma importante contribuição para a compreensão das características dos esforços setoriais de inovação e aprendizagem foi a de Gonçalves e Simões

6 Essa forma de aprendizado não fará parte das análises empíricas devido à falta de informações disponíveis capazes de mensurar esse tipo de aprendizagem.

7 As informações a três dígitos da CNAE foram fornecidas via tabulação especial dos dados da Pintec. 
(2005), ao aplicarem técnicas de análise estatística multivariada a variáveis da Pintec, referentes aos esforços de aprendizagem e incorporação tecnológica. Entre outras particularidades nacionais, os autores destacaram o nível de gastos em atividades inovadoras, maior em setores que foram objetos da política industrial nas décadas de 1960 e 1970 - aeronáutica e siderurgia. Além disso, eles afirmaram que setores com maiores oportunidades tecnológicas apresentam esforços reduzidos em P\&D, o que revela a característica do sistema nacional de passividade e dependência de canais internacionais de transferência tecnológica.

Diferentemente da caracterização dos esforços setoriais de Gonçalves e Simões (2005), nesse trabalho os procedimentos estatísticos para o agrupamento de setores com respeito aos indicadores considerados foram realizados para três anos. Isso porque os "padrōes" são compreendidos como configuraçōes de relaçōes que tendem a se manter com o tempo. Dessa forma, os padrões setoriais foram identificados segundo similaridades comportamentais dos setores nos três períodos pesquisados. ${ }^{8}$

Ao mapear tais padrões, esse estudo pretende mostrar configurações de relações internas e externas à empresa, que traduzem suas atividades tecnológicas. Por isso, nenhuma agregação ex-ante à aplicação da técnica estatística foi realizada, por exemplo, por meio da taxonomia (PAVITT, 1984), ou do uso de classificaçóes dos setores quanto às características em regime tecnológico (MALERBA, 1997). .9 A próxima seção detalha os procedimentos metodológicos utilizados.

\section{Metodologia}

\subsection{A construção dos indicadores}

O procedimento inicial metodológico necessário à análise foi a construção dos indicadores de aprendizagem. Para tanto, foram utilizados dois subconjuntos de informações da Pintec. O primeiro compreende as "fontes de informação", que se referem às ideias utilizadas pelas empresas em seus processos de inovação. Diferentes fontes de informação podem servir de inspiração e orientação aos projetos de inovação das firmas. A Pintec subdivide as fontes internas em dois grupos: os "departamentos de P\&D"; e "outras fontes internas". Estas últimas incluem tanto atividades de $\mathrm{P} \& \mathrm{D}$ não rotinizadas, dispersas em departamentos ou setores de atividade produtiva da firma, como os setores de compras e relaçôes com os fornecedores e os

8 Os critérios para definição dos padrões serão melhores explorados na metodologia.

9 Não obstante, a taxonomia Pavitt (1984) tenha servido como ponto de apoio às análises dos resultados. 
setores encarregados do marketing (PINTEC, 2005). Já as "outras fontes internas" englobam os múltiplos elementos envolvidos em possíveis interações que resultam em aprendizagem e inovação. ${ }^{10}$

O segundo subconjunto de variáveis refere-se à "importância” dada pelas empresas aos gastos realizados em sete atividades de inovação para que as ideias efetivamente se realizem. As diferentes intensidades e formas dos esforços nesses grupos de atividades revelam estratégias diferenciadas de capacitação e aprendizagem.

O Quadro 1 apresenta os indicadores de aprendizagem construídos a partir da combinação de variáveis de FONTES para ideias e as prováveis IMPORTÂNCIAS nas formas de despender gastos associados a tais fontes. A construção das combinações foi realizada observando-se a provável atividade de inovação associada ao uso de determinada fonte de informação como fonte para a inovação. ${ }^{11}$ As duas linhas finais destacam a localização da fonte do conhecimento de cada indicador (se interna ou externa à empresa) e a principal característica do conhecimento envolvido na forma de aprendizagem (se codificado ou tácito).

$\mathrm{O}$ indicador de "aprendizagem pelo P\&D interno", que corresponde teoricamente ao learning by search, procura captar a aprendizagem que emerge dos departamentos de P\&D das empresas. É formado pelo uso desses departamentos como fontes de ideias e pela importância dada pelas empresas aos gastos realizados nessas atividades.

$\mathrm{O}$ indicador de "aprender fazendo" corresponde, teoricamente, ao learning by doing, sendo formado pelo uso das "outras fontes internas da firma - excluindo-se o P\&D” e pela importância dos gastos com "projetos industriais e outras preparaçôes técnicas”. Espera-se com esse indicador captar a intensidade da aprendizagem derivada de atividades internas de P\&D ocasionais, além daquela que emerge das atividades de engenharia de produção e qualidade, quando da execução de procedimentos técnicos, previstos ou não em projetos, destinados a efetivar a implementação de inovações de produtos e processos. Os procedimentos incluem, por exemplo,

10 Nesse artigo, focou-se exclusivamente no aprendizado fruto dos esforços unilaterais. Isso exclui, por exemplo, a aprendizagem derivada da cooperação, a qual possui natureza definida por esforços conjuntos das empresas com seus parceiros, normalmente voltados a objetivos predefinidos. A natureza diferenciada dessas formas de aprender justifica a compreensão de que, analisadas separadamente, essas formas particulares de aprendizagem podem fazer mais sentido.

11 Não se está assumindo com isso que exista uma correspondência absoluta entre fontes de ideias e os gastos com atividades de inovação. De fato, ideias surgidas nos departamentos de P\&D (learning by search) podem ser executadas por meio de gastos com P\&D externo (learning by advanced S\&T). Contudo, os indicadores assumem que há uma probabilidade maior de que os gastos sejam realizados nos departamentos de P\&D da própria empresa, nesse caso. 
atividades tecnológicas industriais básicas como metrologia, normalização, ensaios e testes, assim como mudanças em procedimentos de produção e em padrões e métodos de trabalho, ou transformação de plantas e desenhos voltados à definição de características operacionais de produção e distribuição.

O indicador denominado "aprendizagem por treinamento" é derivado, teoricamente, do learning to learn e foi formado pelo uso dos centros de capacitação profissional como fonte de ideias para a mudança técnica, enquanto a importância com os gastos em treinamento foi considerada a forma típica de gasto associada a esse tipo de aprendizagem.

$\mathrm{O}$ indicador de "C\&T avançada", que teoricamente corresponde ao learning from advanced $S \mho T$, procura captar a aprendizagem derivada das interaçôes das empresas com a estrutura de ciência e tecnologia avançada. As "universidades" e as "conferências e publicações especializadas" são consideradas as fontes para as ideias, enquanto os gastos para a realização de tais ocorrem na aquisição externa de P\&D de outras organizações, instituições ou empresas.

Para inferir sobre a "aprendizagem por interação", learning by interacting, três indicadores foram construídos. O primeiro - "aprendizagem com fornecedores" - procura captar a aprendizagem surgida das interaçôes à montante. Os "fornecedores" são as fontes de informação para as ideias, sendo que e a importância dos gastos está na "aquisição de máquinas e equipamentos". Para o segundo indicador, "aprendizagem com clientes", esses foram considerados fontes de ideias, enquanto a importância do gasto recai na "introdução da inovação tecnológica no mercado", o que inclui pesquisas e testes de mercado. Além da publicidade para o lançamento da inovação, foi considerada a forma de realizar a ideia. $\mathrm{O}$ terceiro indicador foi formado para captar a aprendizagem derivada das "outras fontes externas de interação", observando-se, especificamente, o estímulo gerado por conferências, encontros, feiras e exposições, com a difusão de conhecimentos capazes de gerar novas ideias entre concorrentes, bem como a importância das empresas de consultoria e dos concorrentes, como agentes integrados à indústria, capazes de fornecer ideias ao processo de inovação.

Finalmente, o indicador de "aprendizagem por imitação", que corresponde ao learning by imitating, considera os "concorrentes" e as "licenças, patentes e know-how externo" como fontes de ideias para as inovaçôes, enquanto a importância com a "aquisição de outros conhecimentos externos", incluindo a aquisição de licenças, patentes e know-how externo, foi considerada dispêndios associados. 


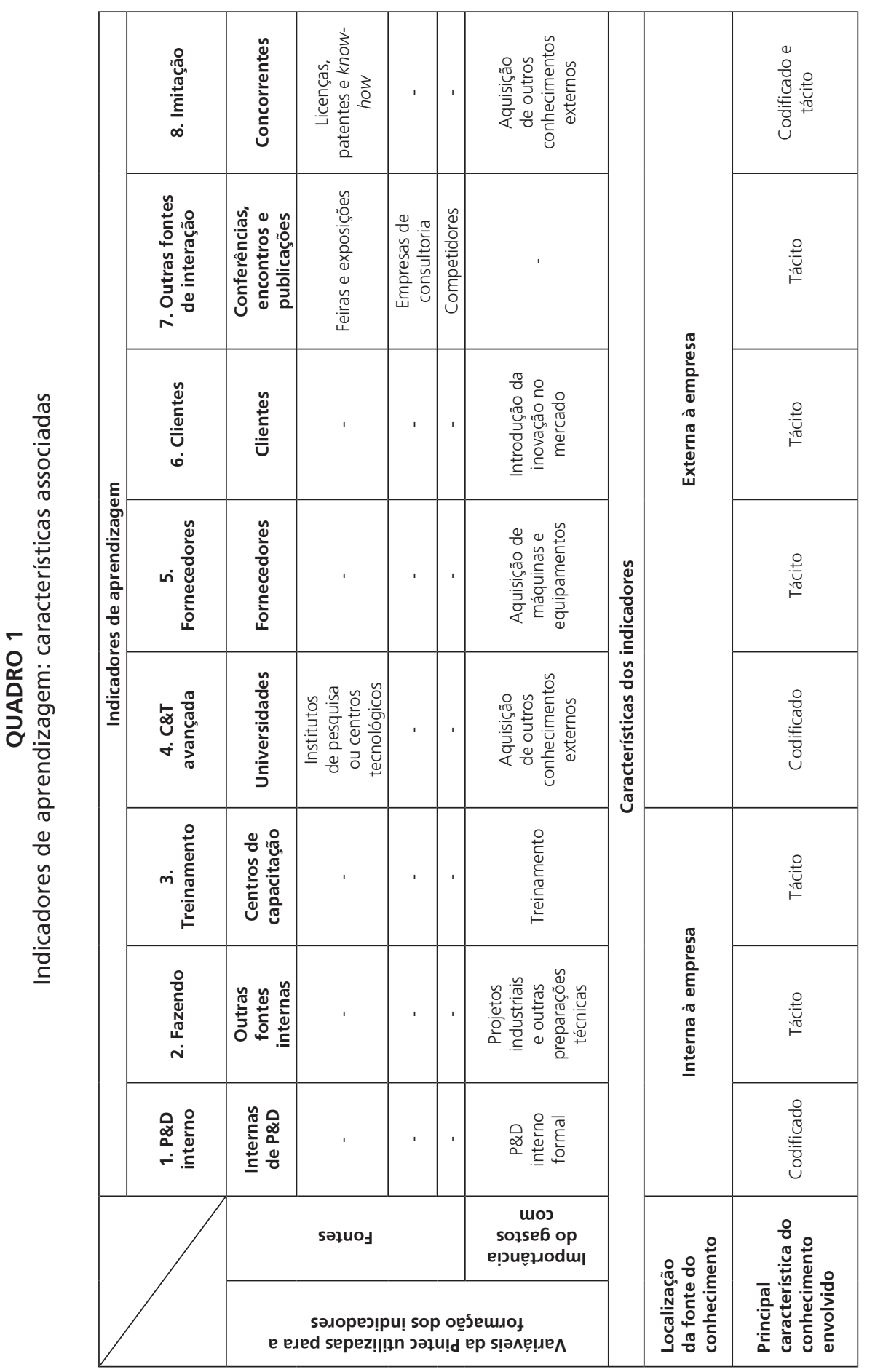

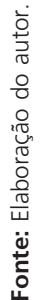


No que diz respeito à construção desses indicadores, as possibilidades de respostas das empresas inovadoras às questôes formuladas pela Pintec é sempre qualitativa: de importância alta, média, baixa ou irrelevante. Esses atributos qualitativos da Pintec foram transformados em quantitativos para que as técnicas estatísticas pudessem ser utilizadas. O procedimento consistiu na substituição dos qualitativos: "alta", "média" e "baixa ou irrelevante" para, respectivamente, "1", "0,66" e "0,167". ${ }^{12}$ Assim, os indicadores foram formados a partir de uma média ponderada da importância atribuída pelo conjunto das empresas inovadoras de cada setor às variáveis selecionadas para a composição desses indicadores.

$\mathrm{Na}$ sequência, apresentam-se os resultados da aplicação do ferramental de análise estatística multivariada, especificamente a técnica de clustering, a partir da qual quatro grupos de setores foram formados com respeito à intensidade do uso dos indicadores.

\subsection{Aplicação da técnica de cluster. a formação dos padrões}

Para a formação dos padrões, foi empregada a técnica de clustering de análise estatística multivariada. Tecnicamente, um cluster pode ser visto como um conjunto de dados que guardam semelhanças entre si. Trata-se de uma técnica de agrupamento cujo método tem por objetivo a separação de objetos ou observações em classes, de modo que os elementos classificados em um grupo apresentem alto grau de similaridade. Uma descrição genérica do objetivo de um clustering seria o de maximizar a homogeneidade dentro de um cluster enquanto se maximiza a heterogeneidade entre os clusters (HRUSCHKA; EBECKEN, 2000).

Existem vários métodos de agrupamento. Neste trabalho optou-se por um não hierárquico, denominado $K$-means. ${ }^{13}$ Os casos a serem agrupados são os setores, enquanto as variáveis que determinam os agrupamentos correspondem aos indicadores

12 O valor para a especificação qualitativa "baixa ou irrelevante" segue a valoração sequencial das informações alta e média. O valor "0,167" é a média entre "0,33" e "0,00", valores atribuídos para "baixa" e "irrelevante", respectivamente. Isso deve-se à disponibilização dos dados exclusivamente agregados.

13 A meta do algoritmo K-médias é encontrar um particionamento ótimo para dividir um número de objetos em kgrupos, fazendo com que os objetos se movam de forma a agruparem-se minimizando a variância intragrupos e maximizando a variância entre grupos. O processo interativo é realizado por combinação de elementos em k grupos, até que se obtenha uma combinação que maximize o cálculo das variâncias entre grupos e que minimize o cálculo das variâncias intragrupos. Em cada um dos três exercícios deste trabalho, foram necessárias apenas três interações para que se obtivessem os resultados ótimos. 
de aprendizagem, apresentados no Quadro 1. Cada um dos 93 setores de atividade industrial brasileira é caracterizado segundo os oito indicadores.

Sob o método K-means, o número de clusters deve ser definido, a priori. De maneira crescente, foram testados 2, 3 e 4 clusters; apenas no último caso os valores da "estatística p" apresentaram significância < 5\% para todos os indicadores.

Nesse exercício os dados foram padronizados, ${ }^{14}$ fazendo com que as médias de cada indicador chegasse a 0 e o desvio padrão igual a " 1 ”. Dessa forma, somando-se a magnitude de qualquer dos indicadores, chegaremos ao zero.

\section{Discussão: os padrões setoriais de aprendizagem da indústria brasileira}

Essa seção apresenta e analisa os quatro padrões setoriais de aprendizagem formados com a aplicação do ferramental estatístico exposto anteriormente. As características de aprendizagem que distinguem os padrões são identificadas a partir de três gráficos para cada padrão, correspondentes às três Pintecs (2000, 2003 e 2005). Os gráficos plotam as intensidades médias do uso de cada forma de aprendizagem representada nos indicadores. Dos gráficos se retiram as características semelhantes da trajetória de aprendizagem (2000, 2003 e 2005) que definem os padrões.

Destaca-se que, uma vez que os agrupamentos (clusterings) foram realizados de maneira independente em cada um dos três anos, os setores que compõem os padrões poderiam modificar suas formas de aprender ao longo dos anos e, assim, migrarem de um padrão para outro. Dessa forma, definiu-se que a presença de um setor de atividade produtiva em dois dos três períodos em análise seria um indicador suficiente para considerá-lo membro desse padrão. ${ }^{15}$ A seção 4.5 analisa os principais movimentos de migrações.

Estatisticamente essa arbitrariedade significa que, supondo equiprobabilidade de um setor estar em determinado agrupamento, as chances, por exemplo, de um setor classificado no agrupamento que forma o padrão 1 no primeiro período (Pintec I) estar também nos agrupamentos que formam esse padrão no segundo (Pintec 2) e

\footnotetext{
14 Padronização significa tornar as médias dos indicadores igual a zero e desvio padrão igual a 1 . O benefício dessa técnica está representado nos gráficos que permitem a visualização dos padrões. Especificamente, a técnica aponta as formas de aprendizagem acima ou abaixo da média geral em cada padrão.

15 Esse critério foi definido observando-se a noção de padrões utilizada nas ciências biológicas, da qual se deriva que os padrões enquanto configurações de relações no interior de um sistema são passíveis de mutações aleatórias.
} 
no terceiro período (Pintec 3) é de $1 / 4 \times 1 / 4=1 / 16$, ou seja, 6,25\%. Já a chance de um setor classificado no agrupamento que forma o padrão 1 , por exemplo, estar também no agrupamento 2 ou 3 é de duas chances em oito possíveis, ou seja, 1/4, ou ainda, 25\%. Apoiando-se nessas probabilidades, compreende-se que o formato sugerido para a obtenção dos padrões é confiável.

Os resultados revelaram que apenas 33 setores da atividade industrial ${ }^{16}$ estiveram presentes nos três clusters que formam cada padrão, ou seja, são casos em que não houve migração entre eles. Outros 47 estiveram presentes em dois dos três clusters. Apenas 13 setores não foram classificados por terem sido enquadrados em um padrão diferente em cada ano. ${ }^{17}$

O Quadro 2 apresenta os setores que formam os quatro padrões de aprendizagem identificados para a indústria brasileira. Nota-se certo grau de correspondência dos resultados entre os padrōes de aprendizagem e os padrōes de mudança tecnológica, de Pavitt (1984). ${ }^{18}$ É importante lembrar, contudo, que ainda que este último trabalho tenha utilizado variáveis para medir "aprendizagem" - e por isso será eventualmente utilizado como referência às análises a seguir -, seu objetivo, sua metodologia e o período de análise são absolutamente distintos do presente estudo, o que inviabiliza uma análise comparativa dos resultados.

16 O termo "setor da atividade industrial" refere-se ao conjunto de empresas classificadas na mesma atividade da indústria de transformação, ao nível dos três dígitos da CNAE. O melhor nível de desagregação disponibilizado pela Pintec.

17 Especulações sobre as razões pelas quais esses setores foram enquadrados em padrões diferentes a cada ano estão fora do escopo principal desse artigo. Uma investigação mais detida deveria considerar desde razões relacionadas às amostras da Pintec para cada ano, até mudanças de comportamento dos agentes, relacionadas a características como adaptação à demanda ou resposta a políticas governamentais, por exemplo.

180 grau de correspondência pode ser observado entre o padrão 1, dos setores intensivos em aprendizagem na esfera da produção e os setores intensivos em escala de Pavitt (1984), assim como o padrão intensivo em aprendizagem à montante e os setores dominados por fornecedores; os intensivos em múltiplas formas de aprendizagem e os baseados em ciência e os intensivos em aprendizagem interna e à jusante. O uso das fontes de informação para a inovação nos três trabalhos é a melhor explicação para a semelhança nos resultados. Cabe destacar, no entanto, que se trata de trabalhos com objetivos e metodologias diferentes, especialmente no caso de Pavitt (1984). 
QUADRO 2

Os Padrões setoriais identificados para a indústria brasileira

\begin{tabular}{|c|c|c|c|c|}
\hline & $\begin{array}{l}1 \text { - Intensivo em } \\
\text { aprendizagem na } \\
\text { esfera produtiva }\end{array}$ & $\begin{array}{l}2 \text {-Intensivo em } \\
\text { aprendizagem à } \\
\text { montante }\end{array}$ & $\begin{array}{l}3 \text { - Intensivo em } \\
\text { múltiplmas formas }\end{array}$ & $\begin{array}{l}4 \text { - Intensivo em } \\
\text { aprendizagem in- } \\
\text { terna e à jusante }\end{array}$ \\
\hline \multirow{14}{*}{ 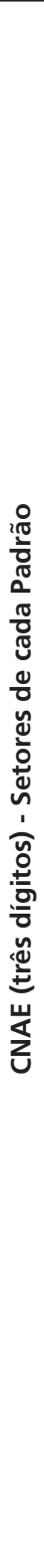 } & $\begin{array}{l}151 \text { - Carnes e pes- } \\
\text { cado }\end{array}$ & $\begin{array}{l}141 \text { - Extração de } \\
\text { pedra, areia e argila }\end{array}$ & $\begin{array}{l}245 \text { - Produtos } \\
\text { farmacêuticos }\end{array}$ & $\begin{array}{l}241 \text { - Químicos } \\
\text { inorgânicos }\end{array}$ \\
\hline & $\begin{array}{l}153 \text { - Óleos vegetais } \\
\text { animais }\end{array}$ & $\begin{array}{l}142 \text { - Extração de } \\
\text { outros minerais }\end{array}$ & $\begin{array}{l}246 \text { - Defensivos } \\
\text { agrícolas }\end{array}$ & $\begin{array}{l}243 \text { - Resinas, } \\
\text { elastômeros, fibras } \\
\text { artificiais e sinté- } \\
\text { ticos }\end{array}$ \\
\hline & 154 - Laticínios & $\begin{array}{l}155 \text { - Moagem, fabr. } \\
\text { de amiláceos e de } \\
\text { rações }\end{array}$ & $\begin{array}{l}301 \text { - M\&E para } \\
\text { informática e es- } \\
\text { critório }\end{array}$ & $\begin{array}{l}\text { 248- Tintas, verniz- } \\
\text { es, esmaltes, lacas } \\
\text { e produtos afins }\end{array}$ \\
\hline & 156 - Açúcar & $\begin{array}{l}158 \text { - Produtos ali- } \\
\text { mentícios }\end{array}$ & $\begin{array}{l}313-\text { Condutores } \\
\text { elétricos isolados }\end{array}$ & $\begin{array}{l}249 \text { - Produtos } \\
\text { químicos diversos }\end{array}$ \\
\hline & 157 - Café & $\begin{array}{l}171 \text { - Fibras têxteis } \\
\text { naturais }\end{array}$ & $\begin{array}{l}314 \text { - Pilhas, bate- } \\
\text { rias e acumuladores } \\
\text { elétricos }\end{array}$ & $\begin{array}{l}284 \text { - Artigos de } \\
\text { cutelaria, e ferra- } \\
\text { mentas manuais }\end{array}$ \\
\hline & 159 - Bebidas & $\begin{array}{l}175 \text { - Acabamento em } \\
\text { fios e tecidos }\end{array}$ & $\begin{array}{l}329 \text { - Equip. telefo- } \\
\text { nia e radiotelefonia } \\
\text { e de transmi. de TV } \\
\text { e rádio }\end{array}$ & $\begin{array}{l}291 \text { - Motores, } \\
\text { bombas, compres- } \\
\text { sores e equip. de } \\
\text { transmissão }\end{array}$ \\
\hline & 172 - Fiação & $\begin{array}{l}176 \text { - Artefatos de teci- } \\
\text { dos e de outros têxteis }\end{array}$ & $\begin{array}{l}332 \text { - Instrumentos } \\
\text { de medida, teste e } \\
\text { controle }\end{array}$ & $\begin{array}{l}292-\mathrm{M} \& \mathrm{E} \text { de uso } \\
\text { geral }\end{array}$ \\
\hline & 211 - Celulose & 177 - Tecidos de malha & $\begin{array}{l}341 \text { - Inst. ópticos, } \\
\text { fotográficos, etc... }\end{array}$ & $\begin{array}{l}295 \text { - M\&E p/ } \\
\text { extração mineral e } \\
\text { construção }\end{array}$ \\
\hline & 234 Álcool & $\begin{array}{l}181 \text { - Confecção de } \\
\text { vestuário e acessórios }\end{array}$ & $\begin{array}{l}342 \text { - Automóveis, } \\
\text { camionetas e utili- } \\
\text { tários }\end{array}$ & $\begin{array}{l}296 \text { - Outras M\&E } \\
\text { de uso na extração } \\
\text { mineral }\end{array}$ \\
\hline & 263 - Cimento & $\begin{array}{l}182 \text { - Vestuário de } \\
\text { segurança profissional }\end{array}$ & $\begin{array}{l}160 \text { - Caminhões e } \\
\text { ônibus }\end{array}$ & $\begin{array}{l}316 \text { - Material elé- } \\
\text { trico para veículos }\end{array}$ \\
\hline & $\begin{array}{l}271 \text { - Ferrogusa e } \\
\text { ferroligas }\end{array}$ & $\begin{array}{l}192 \text { - Artigos de via- } \\
\text { gem e artefatos de } \\
\text { couro }\end{array}$ & $\begin{array}{l}334-\text { Produtos do } \\
\text { fumo }\end{array}$ & $\begin{array}{l}318 \text { - Fabric. e } \\
\text { reparação de má- } \\
\text { quinário e mat. } \\
\text { elétricos }\end{array}$ \\
\hline & $273-$ Tubos & 193 - Calçados & & $\begin{array}{l}321 \text { - Material } \\
\text { eletrônico básico }\end{array}$ \\
\hline & $\begin{array}{l}274 \text { - Metalurgia de } \\
\text { não ferrosos }\end{array}$ & $\begin{array}{l}201 \text { - Desdobramento } \\
\text { de madeira }\end{array}$ & & $\begin{array}{l}359 \text { - Outros } \\
\text { equipamentos de } \\
\text { transporte }\end{array}$ \\
\hline & $\begin{array}{l}289 \text { - Produtos diver- } \\
\text { sos de metal }\end{array}$ & $\begin{array}{l}202 \text { - Produtos de } \\
\text { madeira e material } \\
\text { trançado }\end{array}$ & & $\begin{array}{l}232 \text { - Produtos de- } \\
\text { rivados do petróleo }\end{array}$ \\
\hline
\end{tabular}

(continua) 
QUADRO 2

Os Padrões setoriais identificados para a indústria brasileira

\begin{tabular}{|c|c|c|c|c|}
\hline & $\begin{array}{l}1 \text { - Intensivo em } \\
\text { aprendizagem na } \\
\text { esfera produtiva }\end{array}$ & $\begin{array}{c}2 \text {-Intensivo em apre- } \\
\text { ndizagem à } \\
\text { montante }\end{array}$ & $\begin{array}{l}3 \text { - Intensivo em } \\
\text { múltiplmas formas }\end{array}$ & $\begin{array}{l}4 \text { - Intensivo em } \\
\text { aprendizagem in- } \\
\text { terna e à jusante }\end{array}$ \\
\hline \multirow{20}{*}{ 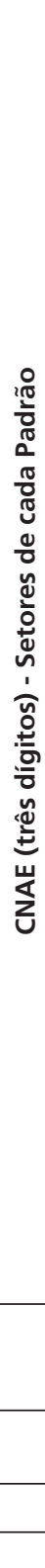 } & $\begin{array}{l}293 \text { - Tratores e M\&E } \\
\text { p/ agricultura }\end{array}$ & $\begin{array}{l}213 \text { - Embalagens de } \\
\text { papel ou papelão }\end{array}$ & & $\begin{array}{l}297 \text { - Armas, } \\
\text { munições e equipa- } \\
\text { mentos militares }\end{array}$ \\
\hline & $\begin{array}{l}294 \text { - Máquinasfer- } \\
\text { ramentas }\end{array}$ & $\begin{array}{l}214 \text { - Papel, papelão, } \\
\text { cartolina e cartão }\end{array}$ & & $\begin{array}{l}351 \text { - Constr. de } \\
\text { embarcações e } \\
\text { veículos ferroviários }\end{array}$ \\
\hline & $\begin{array}{l}312 \text { - Equipamentos } \\
\text { de energia elétrica }\end{array}$ & $\begin{array}{l}221 \text { - Edição, im- } \\
\text { pressão e reprodução }\end{array}$ & & $\begin{array}{l}353 \text { - Construção, } \\
\text { montagem de } \\
\text { aeronaves }\end{array}$ \\
\hline & $\begin{array}{l}344 \text { - Peças para } \\
\text { veículos }\end{array}$ & $\begin{array}{l}242 \text { - Prod. químicos } \\
\text { orgânicos }\end{array}$ & & \\
\hline & & $\begin{array}{l}251 \text { - Artigos de } \\
\text { borracha }\end{array}$ & & \\
\hline & & $\begin{array}{l}252 \text { - Produtos de } \\
\text { material plástico }\end{array}$ & & \\
\hline & & $\begin{array}{l}261 \text { - Vidro e produtos } \\
\text { de vidro }\end{array}$ & & \\
\hline & & $\begin{array}{l}263 \text { - Artefatos de } \\
\text { concreto, cimento e } \\
\text { similares }\end{array}$ & & \\
\hline & & $\begin{array}{l}264 \text { - Produtos } \\
\text { cerâmicos }\end{array}$ & & \\
\hline & & $\begin{array}{l}269 \text { - Aparelhamento } \\
\text { de pedr., fabric. de cal.. }\end{array}$ & & \\
\hline & & 275 - Fundição & & \\
\hline & & $\begin{array}{l}281 \text { - Estruturas metáli- } \\
\text { cas e de caldeira }\end{array}$ & & \\
\hline & & $\begin{array}{l}282 \text { - Tanques, caldei- } \\
\text { ras, etc. metálicos }\end{array}$ & & \\
\hline & & $\begin{array}{l}283 \text { - Metalurgia do pó } \\
\text { e tratamento de metais }\end{array}$ & & \\
\hline & & $\begin{array}{l}299 \text { - Manutenção e } \\
\text { reparação de M\&E }\end{array}$ & & \\
\hline & & $\begin{array}{l}315 \text { - Fabric. de lâm- } \\
\text { padas e equip. de ilu- } \\
\text { minação }\end{array}$ & & \\
\hline & & $\begin{array}{l}343 \text { - Cabines, carro- } \\
\text { cerias e recuperação de } \\
\text { motores. }\end{array}$ & & \\
\hline & & $\begin{array}{l}361 \text { - Artigos do mo- } \\
\text { biliário }\end{array}$ & & \\
\hline & & 369 - Produtos diversos & & \\
\hline & & 371 - Reciclagem & & \\
\hline
\end{tabular}

Fonte: Elaboração do autor.

(conclusão) 
A seguir, são apresentadas e analisadas as formas de aprendizagem que definem os quatro padrões de aprendizagem na indústria brasileira.

\subsection{Padrão 1 - Intensivo em aprendizagem na esfera produtiva}

Como poderá ser notado na continuidade do texto, esse é o padrão menos definido dos quatro identificados. O Gráfico 1 mostra que a maior semelhança está entre os anos de 2000 e 2005 (Pintecs I e III), os quais revelam a característica mais marcante dos setores agrupados nesse padrão, ou seja, a intensidade do aprendizado na esfera da produção, marcada por maior tacitividade dos conhecimentos envolvidos.

Para 2003, nota-se maior diversidade no uso de formas de aprendizagem, incluindo-se a P\&D interna. Esse comportamento atípico, acima da média, revela estratégias produtivas e tecnológicas mais ativas, relativamente a outros setores em um período de recessão econômica no país. É provável que o elevado porte médio das empresas inovadoras típicas dos setores agrupados nesse padrão tenha sido decisivo para essa estratégia, por permitir a manutenção ou menor redução relativa de investimentos em áreas muitas vezes não encaradas como essenciais pelas firmas brasileiras, como os próprios departamentos de P\&D.

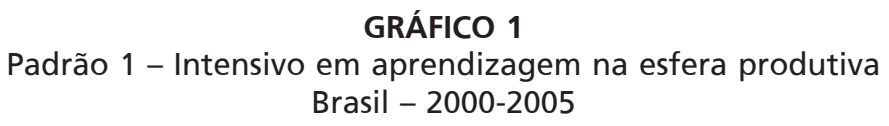

Padrão 1 - 2000

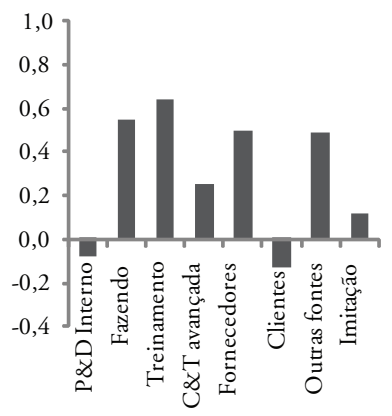

Padrão 1 - 2003

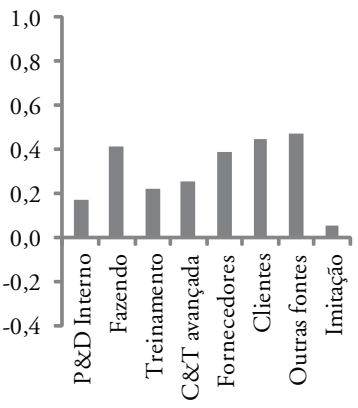

Padráo 1 - 2005

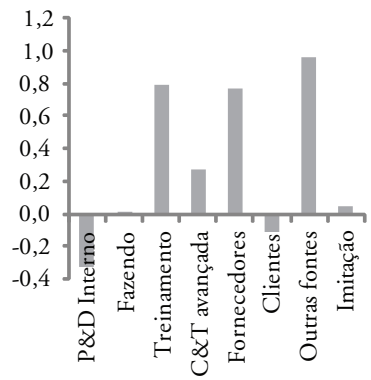

Fonte: IBGE. Pesquisa Industrial de Inovação Tecnológica - Pintec. Elaboração do autor.

Os setores agrupados combinam principalmente esforços internos associados ao "aprender fazendo" e práticas de treinamento com interações extramuros com 
fornecedores, mas também com outras fontes, como empresas de consultoria e concorrentes. $\mathrm{O}$ conhecimento tácito aprendido nessas relaçóes envolve tipicamente a troca de experiências, informaçóes e conhecimentos dos atores envolvidos nas rotinas de produção das fábricas, os quais são complementados fora da empresa por interaçōes tipicamente informais, resultantes do contato face a face ocorridos em encontros e conferências, feiras, exposiçōes e com consultores, bem como nos insights derivados de informações dos concorrentes (outras fontes) e fornecedores. A natureza tácita dos conhecimentos envolvidos nas formas de aprendizagem utilizadas sugere algum grau de dependência do que se aprende internamente com o que se aprende fora da empresa, ou seja, a capacidade de absorver os conhecimentos externos pode estar associada à capacidade de gerar, utilizar e difundir, intrafirma, um conjunto de conhecimentos específicos (COHEN; LEVINTHAL, 1989). Pode-se dizer, ainda, que nos setores que formam o padrão 1 grande parte das inovações implementadas deriva da aprendizagem definida pela maturação das rotinas de produção e de inovação, por meio de processos em que o "saber como" fazer e o "saber quem possui os conhecimentos enraizados em cada atividade" podem ser decisivos (LUNDVALL; FORAY, 1999).

Uma parcela significativa dos setores agrupados nesse padrão poderia ser classificada como "baseados em escala", segundo a taxonomia de Pavitt (1984) sobre a mudança tecnológica. Esse autor destacou os departamentos de engenharia de produção e seus fornecedores de equipamentos e instrumentos como as principais fontes de aprendizado.

Essas formas de aprender, intensas entre os setores do padrão 1, são complementadas por outras de alta tacitividade dos conhecimentos envolvidos, bem como pelo uso das fontes avançadas de C\&T. Para isto contribui o elevado conjunto de recursos relativos em posse de empresas de grande porte, típicas dos setores que formam o referido padrão, uma vez que esses recursos colocam as grandes firmas em vantagem para investir na difusão de conhecimentos internos, como nas atividades de treinamento, assim como em acessar diversos tipos de conhecimentos externos, inclusive aqueles de elevada complexidade gerados em universidades e centros de pesquisa.

\section{Padrão 2 -Aprendizagem à montante}

Formado por mais de um terço dos setores estudados - 33, no total -, esse padrão, que se caracteriza pelo aprendizado junto aos fornecedores, revela a intensidade nesses 
setores de uma característica típica do sistema nacional de inovações brasileiro, ou seja, a absorção externa de tecnologias (VIOTTI, 2002).

Soma-se a tal característica nacional a especificidade setorial. Apoiando-se novamente em Pavitt (1984), destaca-se uma parcela significativa de setores que podem ser classificados como "dominados por fornecedores", mas também como "intensivos em escala". Em sua análise dos setores "dominados por fornecedores", Pavitt (1984) ressaltou que a contribuição típica das empresas às suas inovações de produto e processos possui caráter secundário, sendo os fornecedores de equipamentos e outros insumos os principais "geradores" das inovaçóes aplicadas nestas empresas. Tal noção ajuda a entender o comportamento dos setores classificáveis como "dominados por fornecedores", agrupados no padrão 2. Contudo, da presença de setores “intensivos em escala”, poder-se-iam, teoricamente, esperar esforços internos de aprendizagem (by doing) mais intensivos.

O Gráfico 2 permite afirmar, no entanto, que, para pelo menos alguns setores, as práticas de treinamento e imitação são relevantes. Particularmente, os esforços de treinamento sugerem uma percepção das firmas sobre a necessidade de ampliar a capacitação de seus funcionários como forma de habilitar empresas para se adaptarem às constantes transformações técnicas, ampliando, com isso, as possibilidades dessas em melhorar seus processos produtivos com inovações incrementais. Já a imitação sugere esforços a inovações de produto do setor, as quais são, em geral, poucas e de grau restrito (inovações incrementais).

\section{GRÁFICO 2 \\ Padrão 2 - Intensivo em aprendizagem à montante Brasil - 2000-2005}

Padrão 2 - 2000

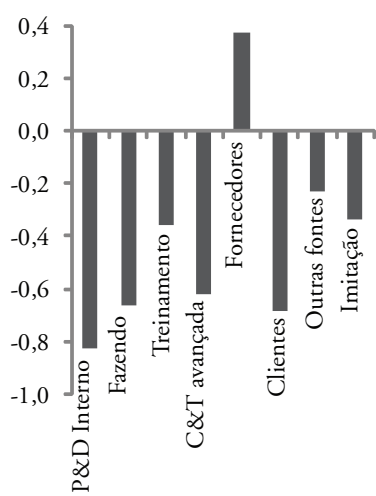

Padrão 2 - 2003

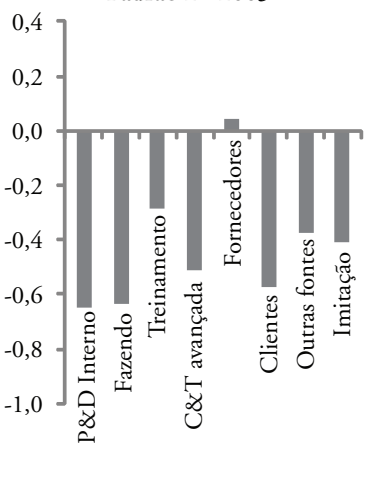

Padrão 2 - 2005

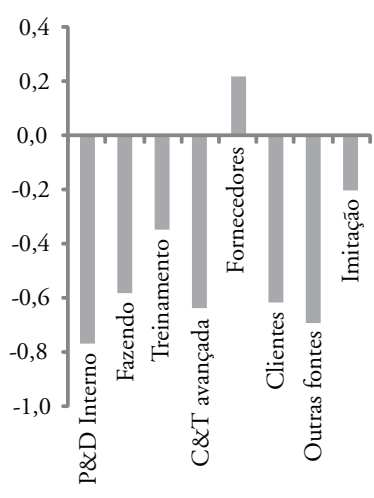

Fonte: IBGE. Pesquisa Industrial de Inovação Tecnológica - Pintec. Elaboração do autor. 
Em resumo, notou-se que um conjunto relevante de setores que compóem a estrutura produtiva do sistema nacional de inovaçóes brasileiro evoluiu tecnologicamente por meio da aprendizagem à montante. Isso já poderia ser esperado, dadas as características típicas de aprendizagem de um grande conjunto de setores agrupados no padrão, podendo ser considerado também um indicador da passividade no processo de geração e uso de conhecimentos economicamente úteis no SNI brasileiro, especialmente pelo fato de a aprendizagem à montante não ser complementada, com intensidade, por outras formas de aprendizagem.

\subsection{Padrão 3 - Múltiplas formas de aprendizagem}

Esse padrão agrupou setores que desenvolvem suas atividades tecnológicas por meio de processos altamente dinâmicos, combinando intensidade e complementaridade no uso das diversas formas de aprendizagem, conforme mostra o Gráfico 3. Habilidades para acessar conhecimentos das universidades podem ser necessárias, mas parecem não ser suficientes para o desenvolvimento do conjunto de soluções que marcam os processos produtivos e inovativos do seleto grupo de setores.

\section{GRÁFICO 3}

Padrão 3 - Intensivo em múltiplas formas de aprendizagem Brasil - 2000-2005
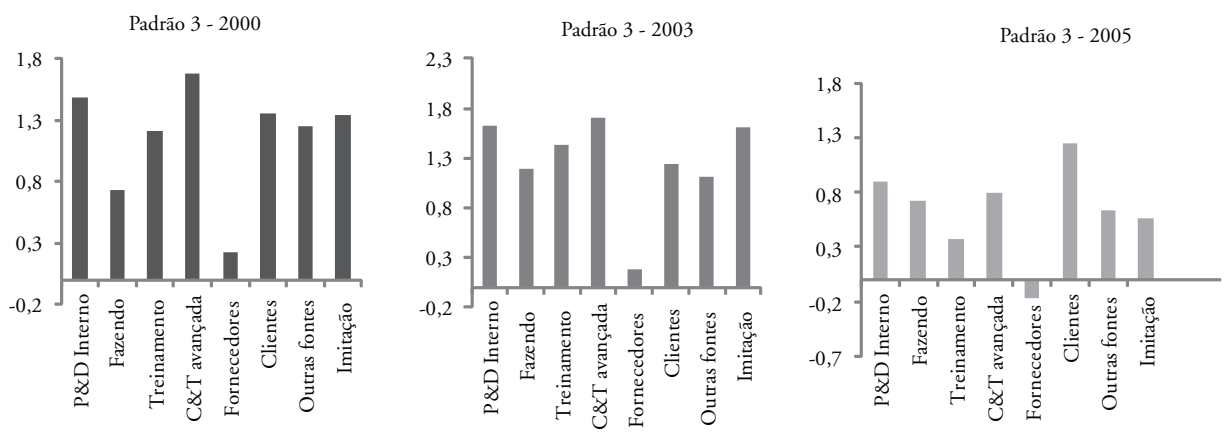

Fonte: IBGE. Pesquisa Industrial de Inovação Tecnológica - Pintec. Elaboração do autor.

A diversidade e a complexidade dos conhecimentos úteis aos referidos setores tornam importante a presença de capacitações que definem os quatro tipos de saber nas empresas (FORAY; LUNDVAL, 1999). Pode-se dizer que os setores agrupados utilizam as diversas formas internas e externas de aprendizagem para acessar uma ampla gama de conhecimentos de caráter tácito e codificado, como forma de manter e ampliar lucratividade e participação de mercado. 
Esta dinâmica competitiva deve-se, em grande magnitude, ao fato de se tratar de empresas de setores intensivos em conhecimentos do atual paradigma tecnológico, especificamente voltados a atividades de microeletrônica (eletroeletrônicos), mas também de biotecnologia (farmacêutico e defensivos agrícolas). Além desses, nota-se também a presença de setores cuja multiplicidade de formas de aprendizagem pode ser explicada pelo volume e variedade de recursos disponíveis nas grandes empresas (produtoras de veículos automotores e fumo), os quais permitem a essas acessar conhecimentos gerados em diversas fontes tecnológicas.

Da complexa dinâmica do aprendizado verificada, destaca-se a combinação do uso das fontes internas de P\&D com as fontes avançadas de C\&T. Como se sabe, a primeira sugere ampliação da capacidade de absorção da segunda, desde que se admita que uma parcela significativa dos conhecimentos gerados nos departamentos de P\&D esteja baseada no desenvolvimento das ciências subjacentes nas universidades. Tal capacidade de absorção pode ser explicada também pelo fato de, em grande medida, os quadros de funcionários dos departamentos de $\mathrm{P} \& \mathrm{D}$ das empresas destes setores serem formados por engenheiros graduados e pós-graduados. Nesse sentido, vínculos informais passados podem ser elementos decisivos ao estabelecimento de canais de comunicação entre as partes.

Em resumo, trata-se de um conjunto de setores marcados por alto dinamismo tecnológico, nos quais a manutenção e ampliação dos lucros e a participação de mercado das empresas parecem estar intimamente associadas aos intensos e diversificados processos de aprendizagem tecnológica.

\subsection{Padrão 4 - Setores intensivos em aprendizagem interna e à jusante}

Como pode-se verificar no Gráfico 4, as empresas dos setores agrupados neste padrão possuem aprendizado centrado em fontes internas, tanto de P\&D como de outros departamentos, as quais são complementadas pelas interações à jusante, ou seja, com clientes.

Os setores que formam o padrão suprem diversos outros ramos industriais com conhecimentos resultantes de suas especializações e experiências, sendo o objeto de seus esforços a concepção e construção de produtos para os sistemas produtivos de seus clientes. São especializados no fornecimento de materiais, aparelhos e peças altamente específicos. É um processo estimulador de interações à jusante. Muitas vezes a especificidade das demandas exige troca de informaçóes e conhecimentos possíveis apenas por contato face a face, inclusive entre pessoal voltado às atividades 
de P\&D. Há, por exemplo, casos em que os produtos são desenvolvidos dentro dos muros das empresas demandantes, como determinadas peças e acessórios para a indústria automobilística. Isso ajuda a explicar a formação de aglomerados produtivos de muitos dos setores agrupados.

\section{GRÁFICO 4 \\ Padrão 4 - Intensivo em aprendizagem interna e à jusante Brasil - 2000-2005}

Padrão 4 - 2000

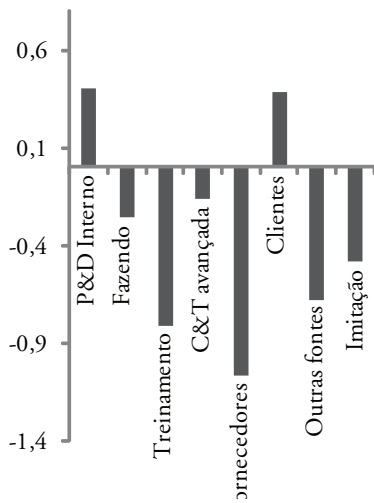

Padrão 4 - 2003

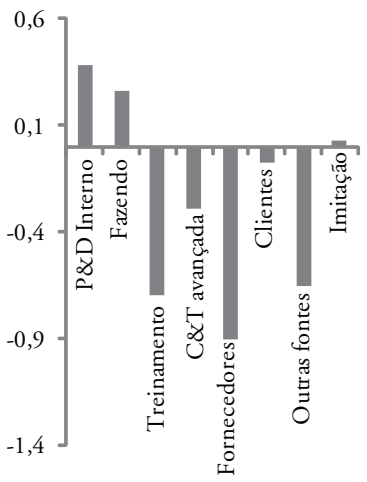

Padrão 4 - 2005

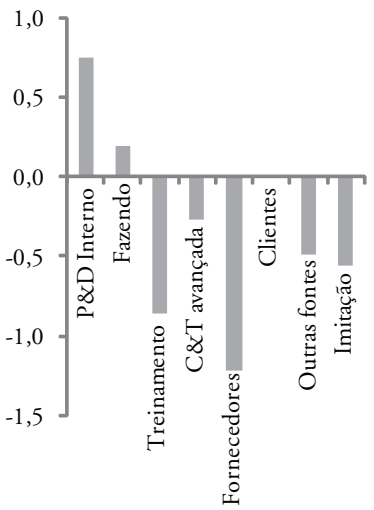

Fonte: IBGE. Pesquisa Industrial de Inovação Tecnológica - Pintec. Elaboração do autor.

Interessante destacar também a presença nesse padrão de três setores privilegiados pela política industrial das décadas de 1950 e 1960. Duas das três grandes empresas estatais que nasceram dessas políticas continuam em operação e ajudam a explicar o elevado nível de importância do indicador de P\&D: a estatal Petrobrás, voltada à produção de derivados de petróleo; e a privatizada Embraer, voltada à construção e montagem de aeronaves. As duas, atualmente, são líderes mundiais em seus segmentos tecnológicos e disputam mercados com poucas outras empresas capazes de operar com nível similar de eficiência. Naturalmente, pode-se esperar que essas firmas utilizem intensamente outras fontes tecnológicas representadas pelos indicadores de aprendizagem. Contudo, outras empresas fazem parte do setor no Brasil, as quais, provavelmente, utilizam com menor intensidade o conjunto das outras formas de aprendizagem. ${ }^{19} \mathrm{~A}$ terceira empresa derivada das políticas mencionadas foi a já falida Engesa (Engenheiros Especializados S/A), voltada à produção 
de equipamentos militares. No lugar da Engesa, o Exército brasileiro tem firmado acordos recentes com empresas privadas para o reaparelhamento de sua frota de equipamentos militares. ${ }^{20}$ Como se sabe, as atividades de desenvolvimento de tecnologias na área militar envolvem segredo industrial, dificuldades de aquisição de tecnologias e, consequentemente, intensidade no uso de fontes tecnológicas internas, especialmente de P\&D. Uma vez que o Exército é o principal cliente, a necessidade de atendimento às exigências dessas demandas torna-se essencial à produção, o que explica a alta intensidade do indicador "clientes".

Dos indicadores com magnitude negativa, nota-se que apenas o das fontes avançadas de C\&T aproximou-se da média nacional. Tais interaçóes podem ser explicadas pela própria procedência universitária dos profissionais voltados a atividades de P\&D das empresas do setor eletro-metal-mecânico e químico, assim como pela potencial relação entre intensidade de $P \& D$ na firma e interação com universidades.

\subsection{As principais migrações entre os padrões de aprendizagem}

Essa seção apresenta e comenta casos de setores agrupados em determinado padrão devido à sua presença em dois períodos apenas. Poder-se-á notar que mudanças radicais são quase inexistentes, como, por exemplo, migrações do padrão de aprendizagem mais dinâmico (padrão 3) para o menos dinâmico (padrão 2). Ao contrário, as transformações mais comuns envolvem padrões que guardam proximidades na intensidade do uso das formas de aprendizagem. A Figura 1 destaca os principais sentidos das migraçóes.

A migração do padrão 1 para o padrão 2 foi verificada do primeiro para o segundo período, com retorno dos setores ao padrão 1 no terceiro período. A migração envolveu os setores de laticínios, fiação, ferro-gusa, metalurgia de não ferrosos e máquinas e ferramentas. Em sua maioria, são setores da indústria metal-mecânica que optaram por estratégias mais defensivas associadas ao uso dos fornecedores como principal fonte tecnológica, no segundo período. Essas estratégias podem estar associadas, por exemplo, ao regime macroeconômico do período que combinava altas taxas de juros e valorização cambial, o que funciona como um poderoso estímulo para importações em detrimento do desenvolvimento tecnológico interno.

20 Em 2007 o Exército brasileiro firmou parceria com a Iveco, subsidiária da Fiat que opera no município de Sete Lagoas - MG, para o desenvolvimento de tanque militar. Do ponto de vista tecnológico, estima-se que um número considerável de patentes se derive do projeto, as quais serão concedidas exclusivamente ao Exército brasileiro. Também a licitação que definirá a renovação da frota de caças de última geração brasileira prevê transferência e, dependendo do vencedor, desenvolvimento de tecnologias no Brasil. 
FIGURA 1

Principais migrações entre os padrões setoriais de aprendizagem

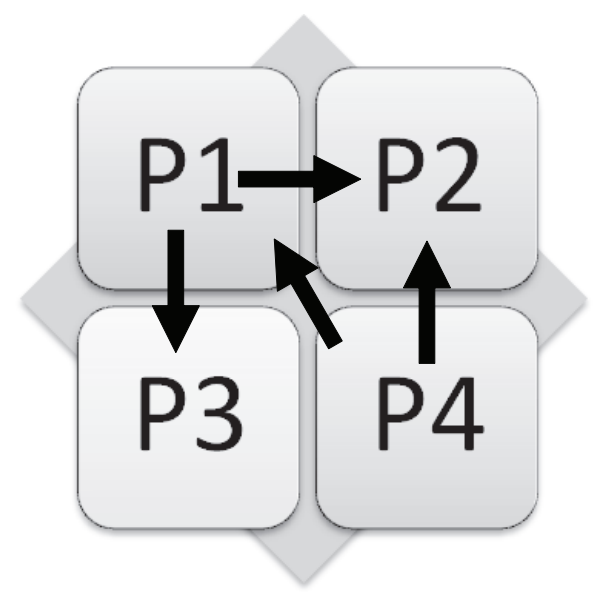

Fonte: Elaboração do autor.

Nota: As flechas indicativas das principais migrações informam apenas os casos em que, pelo menos, cinco setores migraram de um padrão para outro em determinado período.

Houve também setores que migraram do padrão 1 para o padrão 2, do primeiro para o segundo período, e que permaneceram no padrão 2, no terceiro período. São eles: moagem e fabricação de amiláceos e rações; produtos alimentícios; madeira e cortiça; estruturas metálicas; manutenção e reparação de equipamentos e máquinas industriais; e fabricação de cabines e carrocerias. Além desse movimento, destaca-se também a migração de setores do padrão 4 para o padrão 2 no mesmo período. São eles: artefatos têxteis naturais; confecções; artefatos de concretos; e fabricação de lâmpadas. Por se tratar de setores mais elementares, do ponto de vista tecnológico, as migrações sugerem que suas dinâmicas de aprendizado no primeiro período estiveram mais associadas a um comportamento esporádico do que permanente.

No padrão 3, quase toda a migração veio do padrão 1 . Os setores de fumo; máquinas para escritório; fabricação e reparação de equipamentos de telefonia; fabricação de fios, cabos e condutores elétricos; instrumentação e medição agruparam-se no padrão 1 no primeiro período, migraram para o padrão 3 no segundo período e permaneceram nesse padrão no terceiro período. Note-se que a migração envolveu a saída de setores do segundo padrão setorial de aprendizagem mais dinâmico (padrão 1) para o padrão mais dinâmico (padrão 3). Trata-se de setores intensivos no uso e difusão de tecnologias do atual paradigma tecnológico, da informação e comunicação. 
No caso do padrão 4, a imigração mais expressiva envolveu setores presentes nos agrupamentos desse padrão do primeiro e do terceiro períodos e que migraram para o padrão 1 no segundo período. São eles: resinas, elastômeros e fios; M\&E para a extração mineral e construção; outras M\&E para a extração mineral; material elétrico e montagem de aeronaves. Nesse caso, observou-se uma migração de setores difusores do progresso técnico para o padrão setorial que denota aprendizagem focada nas inovações de produto (padrão 4). Em outras palavras, a presença desses setores no padrão 1 no segundo período sugere, também, estratégia esporádica.

Notou-se, dessa pequena explanação sobre as migrações, que, em regra, elas ocorrem de forma suave, ou seja, mudanças bruscas praticamente não são verificadas. Esse fator, ao mesmo tempo em que corrobora a noção teórica de que transformações radicais nos processos de aprendizagem setoriais são pouco frequentes, reforça a efetividade do argumento metodológico adotado na identificação de tais padrões, ou seja, o critério de que é parte de um padrão aquele setor incluído em dois dos três agrupamentos possíveis.

\section{Notas conclusivas}

A identificação de quatro padrões setoriais de aprendizagem na indústria brasileira cumpre o objetivo principal do trabalho, uma vez que foi realizada por meio de método estatístico de ampla aceitação acadêmica, revelada por sua capacidade de apontar padróes entre os casos (setores, nesse trabalho), segundo o comportamento das variáveis (indicadores de aprendizagem). As similaridades expressas nos resultados de aplicação da técnica aos três anos da Pintec representam uma configuração confiável dos padrões identificados, a qual foi reforçada quando analisadas as migrações de setores entre os padrões.

Além disso, ao respeitar o elemento analítico destacado por Malerba (1992) e apontado no referencial teórico, qual seja, o de que o aprendizado associa-se a diversas fontes internas e externas das empresas, o artigo avançou na compreensão da complexidade comportamental capaz de diferenciar as firmas, já apontadas por Pavitt (1984), Malerba (1992), Meeus et al. (1999), entre outros.

Uma importante interpretação dos resultados pode ser também derivada do elemento teórico assinalado por Malerba (1992), de que "o aprendizado é cumulativo e, havendo diversas fontes de conhecimento, as formas de aprendizagem ampliam os estoques de conhecimentos das firmas de diferentes maneiras". A presença de diferentes padrões setoriais de aprendizagem, caracterizados por certa regularidade 
intertemporal, sugere, nessa direção, que o conjunto de conhecimentos tipicamente acumulados pelas empresas que compõem cada padrão é significativamente diferente e que, portanto, pode estar associado a diversas direções da mudança técnica. Essa compreensão permite deduzir também que, quanto maior a diversidade e intensidade das formas de aprendizagem utilizadas pelas empresas, maiores são suas possibilidades de diferenciação de seus concorrentes. Essa diferenciação pode estar cristalizada na diversidade de direções da mudança tecnológica utilizadas pelas firmas. Em outras palavras, a diversidade e intensidade dos processos de aprendizagem podem estar associadas à diversidade nas formas de inovar. Essa derivação, a priori, configura-se em um campo a ser explorado em análises futuras, que respeitem os padrôes setoriais de aprendizagem aqui identificados.

À formação dos padrões baseados em configuraçôes de relações que se repetiram no tempo soma-se, ainda, uma importante derivação normativa, qual seja, a necessidade de observação pelos policy makers das diferenças nos processos de aprendizagem e inovação em muitas indústrias, sendo que, na maioria dos casos, a aprendizagem se deriva muito menos dos tradicionais departamentos de P\&D e da absorção de conhecimentos gerados nas universidades do que da absorção tecnológica via conhecimentos tácitos, exatamente aqueles que, teoricamente, possuem maiores dificuldades de difusão.

Isso significa que a aprendizagem tipicamente utilizada pelas empresas brasileiras provém do acúmulo de conhecimentos obtidos a partir das rotinas de produção das firmas e processos de busca não associados a conhecimentos codificados. O "saber como" e o "saber quem" são as formas de conhecimento que prevalecem e melhor explicam a difusão e o uso de conhecimentos entre as empresas nacionais. Essas formas, ao se reproduzirem no tempo, conformam as memórias organizacionais das firmas, definem suas trajetórias cumulativas de aprendizado e podem representar, por exemplo, empecilhos ao estabelecimento de departamentos formais de P\&D, como poderia ser desejado pelos policy makers.

\section{Referências bibliográficas}

ARROW, K. J. The economic implications of learning by doing. Review of Economic Studies, 29, p. 155-173, 1962.

BROWN, J.S.; DUGUI, P. Organizational of learning and comunities of practies:toward a unified view of working, learning and innovation. Organization Science, v. 2, n. 1. Special 
Issue: Organizational Learning: Papers in Honor of (and by) James G. March. London, (1991), p. 40-57.

BRESCHI, B.; MALERBA, F. Sectoral innovation systems: technological regimes schumpeteriam dynamics and spatial boundaries. In: EDQUIST, C. (Ed.). Systems of innovation: technologies, institutions and organizations. Pinter: London and Washington., 1997, p.130-156.

CAMPOS, B. Aspectos da padronização setorial das inovações na indústria brasileira: uma análise multivariada a partir da Pintec 2000. In: CONGRESSO DA ANPEC. Anais..., 2005

COHEN, W. M.; LEVINTHAL, D. A. Innovation and learning: the two faces of R\&D. The Economic Journal, v. 99 (Sept.), p. 569-596, 1989.

DYER, J.H., Specialized supplier networks as a source of competitive advantage: evidence from the auto industry. Strategic Management Journal, v. 17, n. 4, p. 271-291, 1996.

FORAY, D.; COWAN, R. The economics of codification and the diffusion of knowledge. Oxford: University Press, 1997.

FORAY, D.; LUNDVALL, B. A. The knowledge based economy: from the economics of knowledge to the learning economy. Employment and growth in the knowledge-based economy. OCDE Documents, 1999.

GONSALVES, E.; SIMÕES, R. Padrões de esforço tecnológico da indústria brasileira: uma análise setorial a partir de técnicas multivariadas. Economia - Revista da Anpec, v. 6, n. 2, p. 391-433, 2005.

HRUSCHKA, E. R.; EBECKEN, N. F. F. A clustering algorithm for extracting rules from supervised neural network models in data mining tasks. Int. J. Comput. Syst. Signal, v. 1, n. 1, p. 17-29 (2000).

HAIR, F. J. et al. Multivariate Data Analysis. $5^{\text {th }}$ Edition. New Jersey: Prentice Hall, 1998.

HEDBERG, B. How organizational learn and unlearn? In: NYSTROM, P. C.; STARBUCK, W. H. (Eds.). Handbook of organizational design. London: Oxford University Press, 1981, p. 8-27.

IBGE. Pesquisa Industrial Inovação Tecnológica 2000. Rio de Janeiro: IBGE, 2000.

IBGE. Pesquisa Industrial Inovação Tecnológica 2003. Rio de Janeiro: IBGE, 2003.

IBGEPesquisa Industrial Inovação Tecnológica 2005. Rio de Janeiro: IBGE, 2005.

JENSEN, M. B.; JOHNSON, B.; LORENZ, E.; LUNDVALL, B. A. Forms of knowledge and modes of innovation. Research Policy, n. 36, p. 680-693, 2007. 
LEVIN. Appropiability, R\&D spending and technological progress. American Economic Review, v. 78, n. 2, p. 424-428, Mayo 1988.

LUNDVALL, B. A. Product innovation and user-producer interaction. Industrial, Development Research Series. Aalborg University Press, v. 31, 1986.

. National system of innovation: towards a theory of innovations and interactive learning. London :Printer Publishers, 1992.

. The university in the learning economy. 2002 (DRUID Working Paper, n. 02-06).

LUNDVALL, B. A.; JOHNSON, B.; ANDERSEN, E. S.; DALUM, B. National systems of production, innovation and competence building. In: DRUID Conference, Aalborg, June 2001.

KIM, L.; NELSON, R. Introdução. Tecnologia, aprendizado e inovação: as experiências das economias de industrialização recente. Campinas: Editora Unicamp, 2005.

MALERBA, F. Learning by firms and incremental technological change. The Economic Jornal, p. 845-859, Jul. 1992.

. Sectoral system of innovation and production. Research Policy. CESPRI, Bocconi University, n. 7, p. 247-264, 2002.

MALERBA, F; ORSENIGO, L. Technological regimes and sectoral patterns of innovative activities. Industrial e Corporate Change, v. 6, n. 1, p. 83-117, 1997.

MEEUS, M.; OERLEMANS, L.; HAGE, J. Sectoral patterns of interactive learning. An empirical exploration using an extented resource based model. The Netherlands: Eindhoven Centre for Innovation Studies (Working paper 99.5).

MUROVEC, N.; PRODAN, I. Absorptive capacity, its determinants, and influence on innovation output: cross-cultural validation of the structural model. Technovation, Ed.: Elsevier, v. 29, p. 859-872, 2009.

NELSON, R. R. The co-evoluation of technology, industrial structure and supporting institutions.Industrial and Corporate Change, Oxford University Press, v. 3, n. 1, 1994.

. The evolution of comparative or competitive advantage: a preliminary report on a study. Industrial and Corporate Change, Oxford University Press, v. 5, n. 2, p. 597-617, 1996.

PATEL, P.; PAVITT, K. Pattern of technological activity: their measurement and interpretation. Handbook of the economics of innovation and technological change. Cambridge: Blackwell, 1995.

PAVITT, K. Sectoral patterns of technical change: towards a taxonomy and a theory. Research Policy, v. 13, n. 6, p. 343-373, 1984. 
PAVITT, K.; ROBSON, M.; TOWSEND, J. Technological accumulation, diversification and organization in the U.K. Companies, 1945-1983. Management Science, v. 35, n. 1, p. 81-99, 1989.

SILVERBERG, G.; DOSI, G.; ORSENIGO, L. Innovation, diversity and diffusion: a selforganisation model. The Economic Journal, Priented in Great Britan, 1988.

VIOTTI, E. B. National learning systems - a new approach on technological change in late industrializing economies and evidences from the cases of Brazil and South Korea. Technological Forecasting and Social Change, n. 69, p. 653-680, 2002.

VON HIPPEL, E. Lead users: a source of novel product concepts. Management Science, v. 32, n. 7, p. 791-805, 1986.

ENDEREÇO PARA CORRESPONDÊNCIA:

Pablo Felipe Bittencourt - pablofelipe.bittencourt@gmail.com

Rua José Dutra, bloco 01, ap.102.

Florianópolis, SC - 88036-205

Tel.: (48) 88245759. 
